\title{
The use of enhancement material in grounding system: a review
}

\author{
Aizat Azmi, Noor Azlinda Ahmad, Lau Kwan Yiew, Z. Abdul-Malek \\ Institut Voltan \& ArusTinggi (IVAT), Universiti Teknologi Malaysia, Malaysia
}

\begin{tabular}{l} 
Article Info \\
\hline Article history: \\
Received Jul 16, 2018 \\
Revised Sep 20, 2018 \\
Accepted Oct 4, 2018 \\
\hline Keywords: \\
Enhancement material \\
Grounding impedance \\
Grounding system \\
Soil resistivity
\end{tabular}

Soil resistivity

\begin{abstract}
This paper reviews the improvement of grounding impedance in grounding system by means of enhancement materials. Various enhancement materials for the past 20 years will be reviewed according to their advantages and disadvantages, followed by a focus on the technique for proper measurement set up based on the standard. In addition to that, the condition of enhancement materials under high voltage exposure is reviewed. Many researchers claim that soil resistivity, moisture content, and surrounding environment are the most contributed to the grounding system specifically on the grounding impedance. Hence, the utilization of enhancement materials is essential in order to maintain the grounding system performance.
\end{abstract}

Copyright (c) 2019 Institute of Advanced Engineering and Science. All rights reserved.

Corresponding Author:

Noor Azlinda Ahmad, Institut Voltan \& ArusTinggi (IVAT), Universiti Teknologi Malaysia, 81310, Skudai Johor, Malaysia. Email: noorazlinda@utm.my

\section{INTRODUCTION}

Lightning strike is one of the natural disasters which occur frequently throughout the world. The high magnitudes of current and voltage at rapid rise-times could lead to the destruction of electrical properties and pose serious jeopardy to human safety and life. Besides that, lightning can also damage the structure of the building and can catch fire in those affected area. Therefore, it is very important to have a system which can protect the buildings and avoid lightning stroke. Hence, the grounding system is introduced in order to divert, distribute, and disperse the high currents (charge) of lightning strike into the earth $[1,2]$. An excellent performance of a grounding system is essential, to effectively dissipate the fault currents to the earth [3]. The grounding impedance is reported to be the most important criteria for the grounding system $[4,5]$. Its impedance should be maintained in low levels for long duration. Practically, the back-strike trip could happen when the grounding resistance is high. Soil type is a primary factor to determine the grounding resistance value. Different soil possesses different behavior and characteristic such as resistivity, ionization, and the level of corrosive environment [6]. Soil ionization increases the soil conductivity and decrease the soil resistivity. Meanwhile, corrosion could degrade the electrode conductivity performance. Besides, the weather conditions in which the location of a system is about to be installed, also compose a complex factor on grounding system, due to the variation in the soil resistivity value. The grounding impedance is reported to be vary frequently because of the weather condition and surrounding environment.

In fact, to obtain the low level of impedance in the rocky and sandy soil is somewhat impossible. Therefore, many researchers have introduced several techniques to reduce and maintain the grounding resistant in low level. Such techniques are implementation of reducing agent/backfill materials [7-10] or performed the chemical treatment in the grounding system [11, 12]. These materials are placed inside the trench, where the grounding electrode is installed and mixed with the natural soil [13, 14]. It is like interface contact between the grounding electrode and soil. These materials are reported to have the ability to reduce 
the impedance between the contact areas. Hence, the total soil resistivity will be reduced. In this paper, the overall objective is to review the current enhancement materials of grounding system, with an emphasis on grounding impedance improvement. This paper provides a representative survey of the scientific literature, such as strategies to facilitate grounding impedance improvement in various soil type and geology. As far as the authors concern, there is less explanation about the knowledge on enhancement material in grounding system. Therefore, this paper will elaborate in detail.

\section{GROUNDING SYSTEM MEASUREMENT SETUP}

Institute of Electrical and Electronics Engineers (IEEE) has published a guideline for soil resistivity measurement setup [15]. The Wenner's Four Pin method is a popular technique in soil resistivity. This technique requires several components for the measurement. Such components are probes made of galvanised steel, and potentiometer [16]. The arrangement of Wenner's Four Pin method is illustrated in Figure 1. Various researches have implemented this technique to study the characteristics of soil when mixed with enhancement material. The resistivity output will be the indicator as to monitor the effectiveness of the enhancement material in reducing the grounding impedance. N. H. Shuhada et. al. [9] have conducted a study using Four point method to investigate the bentonite performance at two different soils. Based on the results, this technique can provides different reading of resistance for different soil types. The minimal changes of soil's resistance can be observed. J. Jasni et. al. [7] have utilized the four point method in their study to measure the grounding impedance. Many types of enhancement material have been introduced in the natural soil. As a result, the soil properties have been altered. The physical and chemical changes of the soil are represented by the variation in impedance values. The findings demonstrate that, impedance of soil using different enhancement materials has difference impedance. Hence, this technique is suitable for the measurement for variety soils type and enhancement materials. The soil resistivity based on four point method can be approximated by 1 [5]:

$$
(\rho)=2 \times \pi \times a \times \mathrm{R}
$$

where $a$ is the distance between two consecutive ground stakes (as illustrated in Figure 1 (a)) and $R$ is the soil resistance measured from the test instrument. Basically, the distance between two consecutive ground stakes, $a$ is not fixed. Based on the literature the value of $a$ can be varied depending on the site geology and structure. Besides that, there are various types of instrument used in the measurement. Different models of instrument provide different performance in terms of accuracy, repeatability and reliability which significantly effect to the measurement result. Hence, the selection of instrument is essential while addressing accuracy, repeatability, and reliability requirements.

\section{ENHANCING MATERIALS FOR GROUNDING SYSTEM IMPROVEMENT}

Since 1981, soil characteristic has been identified to have a considerable effect on ground-fault currents. The induced potentials from electromagnetic or resistive (direct earth connection) coupling has the probability to damage the equipment or facility that connected with the grounding system [17]. Moreover, the non-uniformity of soil could lead to higher potential rise specifically in the grounding system [18]. Therefore, the demand of good grounding system increased as to effectively distribute the induced potential to ground.

There are several techniques have been introduced in reducing earth resistance. Such techniques are deep-ground-well Method [19, 20], modification of earth conductor [21-23], and implementation of conductance-enhancement material. Deep-ground-well method is a well-known technique which can perform without the influences of seasonal condition and climate. This technique is suitable for mountainous area. However, the biggest challenge of this technique is to find the optimized depth of deep well in order to get a better resistance reducing role [24]. Besides that, the modification of earth conductor by altering its dimensions (increasing its length) is reported could decreased the impedance [24]. However, due to the high material cost and limited of space, this idea is restricted in many applications. Hence, it has now become a popular practice to use conductance-enhancement material to reduce the earth resistance. Such materials are commonly termed backfill material. Figure 2 demonstrates the location of enhancing material in the grounding system. In the past several decades, researchers have started to explore the suitability of using enhancement materials. The utilization of enhancement material is vital, especially in high soil resistivity area, rocky, and sand soil structure. These materials give a positive significant impact on the grounding system improvement specifically to lowering the grounding impedance. Many researches have been conducted to study various types of enhancement material on their properties, characteristic, and behaviour. The objectives of the research are to find the best material that can improve the grounding impedance for the 
specific type of soil. There are two types of enhancement materials have been introduced. Such materials are natural and chemical.

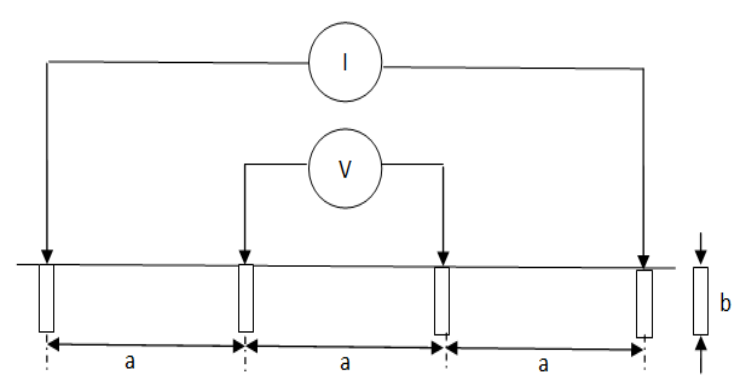

Figure 1. The wenner's four pin four point method $[16,25]$

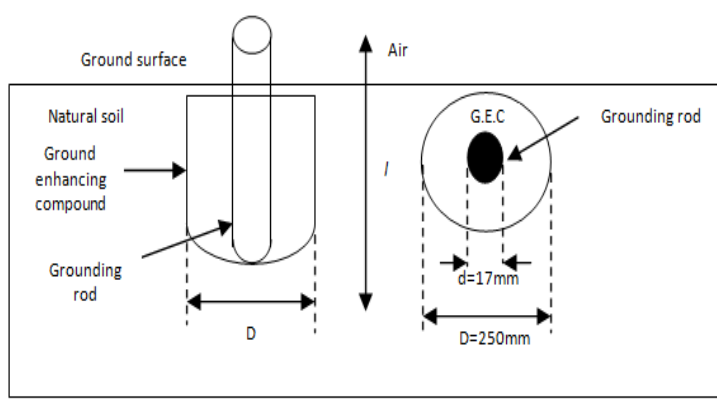

Figure 2. Enhancing material in grounding system [26]

\subsection{Natural Enhancement Material}

Generally, the natural material does not alter the original properties of the soil. Hence, the soil condition can be maintained. On the other hand, the chemical enhancement material could alter the soil properties. Therefore, the soil properties such as ph level, fertility, and mineral are significantly affected. Several studies on natural material have been conducted to find the most suitable material which can efficiently reduce the grounding impedance. G. Eduful et. al. [27] have investigate the characteristic of organic material, Palm kernel oil cake (PKOC) as a backfill material in critical resistance area. Chemical analysis shows that the PKOC consists of relatively large conductive carbonaceous aggregate of $56.22 \%$. Besides, finding demonstrates that PKOC can absorb moisture about two and a half times its weight. Furthermore, PKOC has the ability to provide and maintain an excellent earth resistance-reducing effect for a long period of time. J. Jasni et. al. [7] have continued the investigation on natural material to be used as a grounding enhancement materials in the grounding system. Several materials have been proposed in their research. Such materials are coconut coir peat, paddy dust, and planting-clay soil. The objective of the research is to find the best material to replace bentonite. The best material is chosen based on the lowest impedance and durable. Planting-clay soil has been identified as the most effective grounding filler when compared to bentonite, coconut coir peat and paddy dust as it gives the lowest grounding resistance. The significant different of total impedance between the grounding system which have the grounding filler against those without is observed in this research.

Bentonite is a natural clay where it is widely used as a ground enhancement material (GEM). This material is favored due to its ability to absorb moisture while maintained the humidity in soil. Hence, makes it the best solution to be applied in the grounding system in high soil resistivity area like a rocky soil. In 1980s, Warren R. Jones has introduced bentonite as a backfill material in the grounding system. In this research, he discovers the special characteristic of bentonite which is an excellent conductive backfill. In additions, the bentonite has the ability to absorb up to five times its weight in water and swell up to 13 times its dry volume. The most significant contribution of bentonite in improving the grounding system performance is by reducing its impedance. Hence, improving its conductivity [28]. Since then, various improvement in the electrical properties of grounding system has been reported using bentonite [29, 30].

Z. R. Radakovic et. al. [31] have conducted a study on bentonite material during a real ground fault. The study reveals that, the bentonite form (monolithic block) is maintained which no crack is observed after the exposing to the ground fault current. In addition, the thermal stress of bentonite could increase the grounding resistance for only short period of time. This positive characteristic demonstrates the advantage of bentonite as a backfill material. The further study on the behavior of bentonite under high voltage impulse is carried out by S. C. Lim et. al. [5]. The findings suggested that, bentonite can perform better than other enhancement material under dry condition where its breakdown voltage is the lowest. Besides that, the dissipation heat rate of bentonite is greater than others under alternating high voltage (AHV). The implementation of bentonite material under high soil resistivity has been studied in [29]. The finding demonstrates the grounding resistance can significantly reduce by means of bentonite slurry. $20 \%$ reduction in grounding resistance is obtained in the first 5 month of measurement. Further study on bentonite has been carried out in [9]. They have studied the performance of bentonite material when mixed with two different types of soil namely laterite and peat soil. The findings demonstrate that, bentonite has the ability to reduce 
the grounding impedance for both soils. Weather such as rain fall, temperature, and humidity are the parameters that highly influence the bentonite's performance. However, the main disadvantage of bentonite is high cost as it is often imported especially in the developing country. Therefore, local material which had similar behavior to bentonite is preferred in order to reduce cost of grounding system [7]. Previous research using chemical compound shows a significant improvement on the grounding system [32]. However chemical compound tends to change the nature of the soils. Therefore the use of natural material has addressed the issue while improving the grounding impedance [33].

\subsection{Waste Product Enhancement Materials}

Waste products released from the industry contribute negative impact on environment. Many reports state that pollution issues are mainly came from the industrial waste. It could be an advantage if the waste product can be recycles back for good purposes. Recently, researchers have taken an initiative to study the possibility to use the waste product in a grounding system. Several types of waste products from the industry have been identified in reducing grounding impedance. Chandima Gomesa $e t$. al. [10] have introduced an enhancement material from the metal compounds that contains of iron oxide $\left(\mathrm{Fe}_{2} \mathrm{O}_{3}\right)$. It is reported that, this material is from the steel industry. The finding demonstrates that, the performance of iron oxide is promising where it has reached the same level as the conventional enhancement material.

Fly ash is another type of waste material. This material is produced by the combustion in a coal-fired power plant. The disposal of the fly ash requires considerable capital and generates environmental pollution and ecological effects. Hence, leads to a serious problem for both power generators and government agencies. Shin-Der Chen et. al. [13] have studied the characteristic and performance of fly ash material as a grounding system enhancement material. The finding demonstrates that, after soil stabilization, $35 \%$ of reduction in the grounding impedance is obtained by means of fly ash. This finding proved that the fly ash material can be used as enhancement material. Besides that, the residues from industrial mineral processing which was called as reduction additive (RRA) in [34], has been implemented to achieve a reduction of resistance and extended the life of electrical ground electrodes. The findings demonstrate that, RRA maintained its resistance value for periods greater than a year without the addition of water. Furthermore, 34\% less resistance to impulse current (out standard) with respect to the industrial frequency voltage is observed using RRA. These findings have open more opportunities for the researchers to explore other types of waste materials that can be possibly used as enhancement materials. Furthermore, the environmental pollution can be reduced by means of waste material product in the grounding system. Generally, enhancement materials reduce the contact resistance between the grounding electrode and soil. This is due to the diameter of grounding electrode increased when applied the enhancement material into the grounding system. As a result, the scatter flow resistance is reduced [24]. Besides that, different types, shape [35], and quantity of enhancement materials used in the grounding system will give different response of impedance values [36, 37]. Furthermore, the increment of conductivity by means of enhancement material can potentially lead to quicker electrical current dissipation during a lightning strike [38]. Table 1 summarizes the advantages and disadvantages of various types of enhancement material in grounding system.

\section{GROUNDING ROD DEVELOPMENT USING ADVANCED MATERIALS}

Generally, the conventional steel and copper materials are the most popular materials used to develop a grounding system rod [39-42]. Steel material has a low conductivity and high permeability characteristics. The inductive component of steel material leads to the potential differences. As a result, it could endanger the electronic component in the substation [43]. Besides that, copper material is reported to have several disadvantages such as corrosion, high cost of construction, bad contact with soil due to its hardness, medium conductivity, etc. Among these, corrosion is the main problem which could cause the degradation in the grounding system performance. Corrosion process happens when the copper material reacts with the surrounding environment such as moisture that contains water. This process is normally takes time before fully corroded. Besides that, copper material has an average of conductivity characteristic which could only reduce a minimum amount from the total grounding impedance. In order to compare the performance of these two materials, [44] have taken an initiative to study the performance of galvanized iron (type of steel) and copper material as a grounding system material. The findings demonstrate that, to make the performance of these two materials comparable, the diameter of Galvanized Iron has to be designed larger than that of copper material as the conductivity of copper is better than Galvanized Iron. As a result, more current can pass through the conductor. However, corrosion issue is the biggest issue to these two materials. Therefore, various advance material have been introduced in order to minimize the corrosion issue on the grounding rod. Ruohan Gong et. al. [45] have introduced a new type of grounding material namely a flexible graphite-cooper composited grounding material (FGCG). Graphite material can be considered as an 
advance material due to its characteristic such as highly conductive material and has a bigger dimension (surface) area compared to copper material. Simulation analysis demonstrate that FGCG has small skin effect where the short circle current withstand capacity of FGCG is greater than the conventional metallic material. Moreover, FGCG has demonstrated high thermal capacity capability. To compare the performance of FGCG with the conventional grounding material, Ruohan Gong et. al. [46] have carried out the measurement. The findings demonstrate that, FGCH has less contact resistance than steel due to its bigger diameter and flexibility. Besides that, FGCG and steel have similar performance when grounding body was buried in small granularity soil.

Table 1. Various Types of Enhancement Material in Grounding System

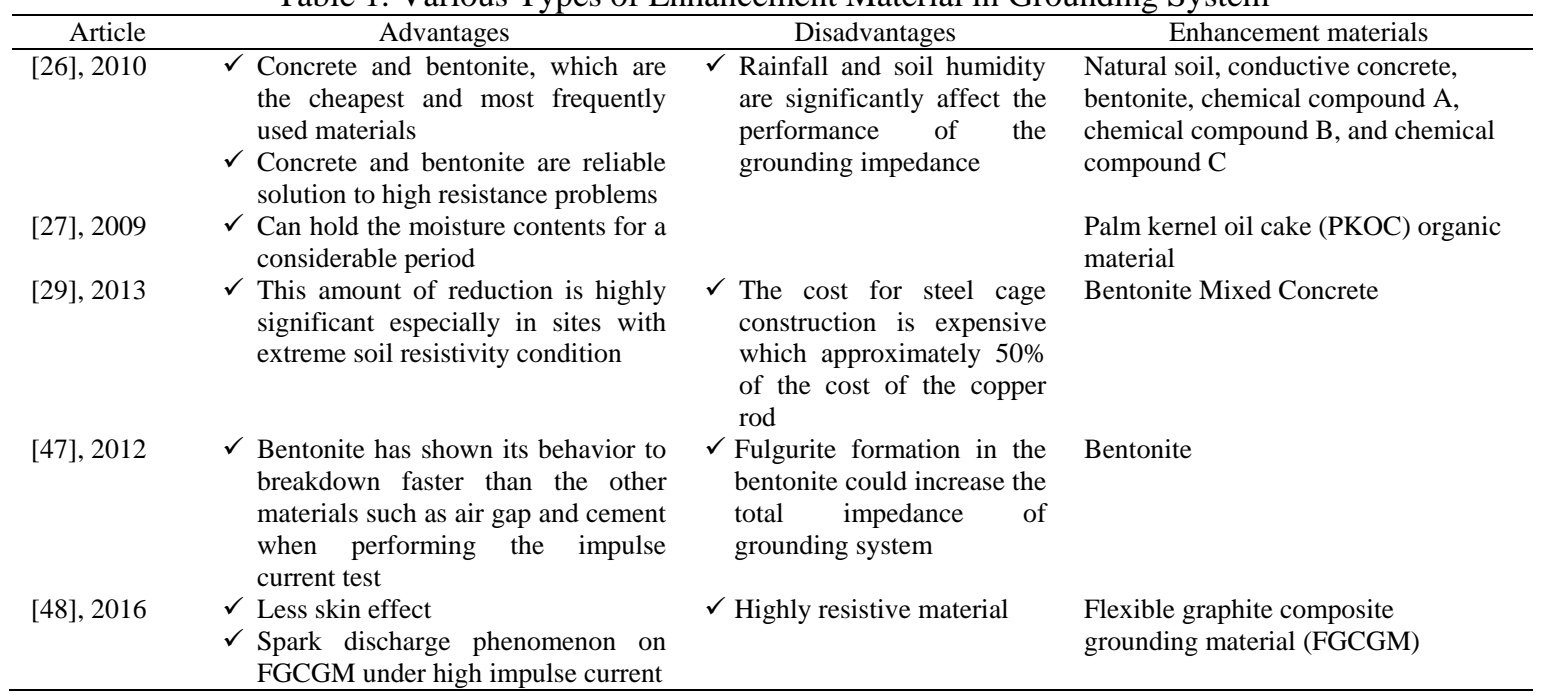

\section{CHARACTERISTIC OF ENHANCEMENT MATERIAL UNDER HIGH IMPULSES VOLTAGE}

Recently, many researches on enhancement material under high voltage are carried out [49-52]. These researches are essential as to investigate the performance and behaviour of enhancement material when high voltage is applied. In other words, these researches help to predict the enhancement material's performance when real lightning strike occurs.

The effect of backfill under lightning condition with that under power frequency condition has been carried out based on a field testing. This investigation is done by W. Hu et. al. [49]. In the research, Wenner's Tri-Probe Method is used to measure the grounding impedance. SMARTEC MI2127 produced by METREL, voltage divider, Rogowski coil and oscilloscopes are used in the impulse field testing. The findings demonstrate that, at both which under power frequency and impulse condition, the conductive backfill is dense with small grain size and the grounding resistance is reduced. Hence, conductive backfill can be used for reducing grounding impedance. Besides that, the effect of the conductive backfill on reducing the grounding resistance under lightning condition is difficult to compare with that under power frequency condition. Rembuluwani Phillip Tshubwana et. al. [51] have conducted a research on enhancement materials under impulse condition. In the research, the performance and characteristic of backfill materials (Soil, Bentonite and Cement) under lightning impulse voltage waveform $(1.2 / 50 \mu \mathrm{s})$ is carried out in the high voltage lab. The finding demonstrates that grounding system under discharge conditions is highly depending on its impulse impedance. When they are massive impulse current flows, it causes the soil around the electrode to breakdown resulting in a decrease in resistance.

Lightning strike with high impulses voltage could generate fulgurites formation. Fulgurites are reported could significantly reduce the performance of grounding system when it formed on the grounding rod surface. These fulgurites are produced when all lightning strikes hit the ground. Fulgurites are classified as a natural tube of glass formed by the fusion of silica sand or rock from a lightning strike. The original properties of material such as physical and electrical are affected by fulgurites formation. Hence, formation of fulgurites can modify the performance of grounding systems. Besides that, fulgurites have a high resistivity characteristic in its original shape. As a result, it can enhance the ground resistance of an electrode system. Zulkifli bin Burhanuddin et. al. [50] have taken the initiative to study the fulgurite formation under high voltage conditions using alternating, direct, and impulse current on two different materials. Such materials are bentonite and sand. In the research it is found that the artificial fulgurites have been 
formed in sand and bentonite under direct voltage. The similar trends are observed under alternativevoltage. The formation of fulgurites takes place when thevoltage exceeds about $10 \mathrm{kV}$. On the other hand, fulgurites did not formed at $250 \mathrm{kV}$ under impulses voltage. Besides that, fulgurites in powder form are significantly different from those of respective original materials in terms of electrical properties. This research has proved that fulgurites formation has a significant impact on the grounding impedance. S. C. Lim et. al. [5] have continued the research on enhancement material behaviour under impulse and alternating high voltage. Their investigation focuses on $50 \mathrm{~Hz}$ of frequency. The research found that, all tested materials under alternating high voltage produced a fulgurites formation. Fulgurites can be formed at bentonite and sand but the latter is possible at much lower alternating high voltage in the presence of moisture. Lightning strike and high impulse voltage are reported to cause failures to electronic system due to overvoltage. Even though the standards are fulfilled, touch and step voltages are controlled, yet the overvoltage issue is still the toughest challenge to be solved $[53,54]$.

\section{CONCLUSION}

The aim of this study was to consider various ways that the enhancement of knowledge and material sciences has played a prominent and relevant role in improving grounding system. The improvement may come from the introduction of enhancement material into a grounding system which will result the reduction of grounding impedance. The performances of the grounding rods with enhancement materials against those without it seem to have a significant difference. The grounding impedance of grounding system using enhancement material is more stable, while the one without enhancement material seem to fluctuate. Besides that, various parameters have been identified that affect the grounding impedance value. Such parameters are the soil resistivity, moisture content, and surrounding environment.

A plenty of enhancement materials have been introduced. These enhancement materials are divided into two categories which are organic and inorganic. Generally, an organic enhancement material is made of natural material while inorganic material consists of a chemical product. Recently, the demand for natural material increased. This is due to the plenty of raw material, inexpensive, and easy to be prepared. The drawback of conventional copper material such as corrosion has been highlighted. Thus, advance materials have been introduced to address the issue. Besides, fulgurites formation is produced when grounding impedance is subjected to high voltage supply. Artificial fulgurites are formed in sand, bentonite, and their mixtures under the application of direct voltage and alternative voltage. Fulgurites formation could reduce the grounding system performance where it increases the impedance.

\section{REFERENCES}

[1] N. Kumarasinghe, "A low cost lightning protection system and its effectiveness," in International lightning detection conference, 1999, pp. 1-6.

[2] E. A. Ammar, Y. Khan, N. Malik, and N. Wani, "Development of Low Resistivity Material For Grounding Resistance Reduction," in Energy Conference and Exhibition (EnergyCon), 2010, vol. 35, pp. 700-703.

[3] I. Ullah, M. N. R. Baharom, H. Ahmad, H. M. Luqman, and Z. Zainal, "Electric Filed Intensity of the Lightning Strikes on Lightning Air Terminals Installed on Building Structures," Int. J. Electr. Comput. Eng., vol. 7, no. 6, pp. 3105-3113, 2017

[4] Z. R. Radakovic, M. V Jovanovic, V. M. Milosevic, and N. M. Ilic, "Application of Earthing Backfill Materials in Desert Soil Conditions," IEEE Trans. Ind. Appl., vol. 51, no. 6, pp. 5288-5297, 2015.

[5] S. C. Lim, C. Gomes, M. Z. A. A. Kadir, G. Nourirad, and Z. A. Malek, "Behaviour of Backfill Materials for Electrical Grounding Systems Under High Voltage Conditions," J. Eng. Sci. Technol., vol. 10, no. 6, pp. 811-826, 2015 .

[6] M. Kizhlo and A. Kanbergs, "Research of the Parameter Changes of the Grounding System," in World Non-GridConnected Wind Power and Energy Conference, WNWEC, 2009, pp. 1-4.

[7] W. F. Wan Ahmad, M. S. A. Rahman, and J. Jasni, "Natural Materials As Grounding Filler for Lightning Protection System," in 30th International Conference on Lightning Protection - ICLP, 2010, pp. 1-6.

[8] L. Chen, J. Chen, T. Liang, and W. Wang, "A Study of Grounding Resistance Reduction Agent Using Granulated Blast Furnace Slag," IEEE Trans. Power Deliv., vol. 19, no. 3, pp. 973-978, 2004.

[9] N. H. Shuhada, N. A. Ahmad, and Z. Adzis, "Grounding Enhancement Material Using Bentonite," J. Adv. Res. Mater. Sci., vol. 24, no. 1, pp. 1-8, 2016.

[10] C. Gomesa, C. Lalitha, C. Priyadarshanee, and E. Engineering, "Improvement of Earthing Systems With Backfill Materials," in 30th International Conference on Lightning Protection - ICLP, 2010, pp. 1-9.

[11] S. C. Lim, C. Gomes, M. Zainal, and A. Ab, "Characterizing of Bentonite with Chemical, Physical and Electrical Perspectives for Improvement of Electrical Grounding Systems," Int. J. Electrochem. Sci., vol. 8, pp. 11429-11447, 2013.

[12] O. E. Gouda, A. Zein, and E. Dein, "Improving underground power distribution capacity using artificial backfill materials," IET Gener. Transm. Distrib., vol. 9, pp. 2180-2187, 2015. 
[13] S. Chen, S. Chen, L. Chen, C. Cheng, and J. Chen, "An Experimental Study on the Electrical Properties of Fly Ash in the Grounding System," Int. J. Emerg. Electr. Power Syst., vol. 7, no. 2, pp. 748-754, 2006.

[14] D. Kokkinos, N. Kokkinos, and J. Koutsoubis, "High frequency behavior of soil improver compounds," in 30th International Conference onLightning Protection (ICLP), 2010, vol. 1400, pp. 1-5.

[15] "IEEE Guide for Measuring Earth Resistivity, Ground Impedance, and Earth Surface Potentials of a Grounding System," IEEE Power Energy Soc., 2012.

[16] P. Simonds, "Designing and Testing Low-Resistance Grounding Systems," IEEE Power Eng. Rev., vol. 20, no. October, pp. 19-21, 2000.

[17] F. Dawalibi, D. Bensted, and D. Bensted, "Soil Effects On Ground Fault Currents," IEEE Trans. Power Appar. Syst., no. 7, pp. 3442-3450, 1981.

[18] M. Hajian and A. A. R. Kazemi, "High Frequency Analysis of Grounding System Using FIT Approach," in Electrical Engineering (ICEE), 2017, pp. 1355-1360.

[19] J. He et al., "Decreasing Grounding Resistance of Substation by Deep-Ground-Well Method," IEEE Trans. Power Deliv., vol. 20, no. 2, pp. 738-744, 2005.

[20] Q. Meng and J. Ma, "A new method to decrease ground resistances of substation grounding systems in high resistivity regions," IEEE Trans. Power Deli, vol. 14, no. 3, pp. 911-916, 1999.

[21] J. He, S. Member, Y. Gao, S. Member, R. Zeng, and W. Sun, "Optimal Design of Grounding System Considering the Influence of Seasonal Frozen Soil Layer,” vol. 20, no. 1, pp. 107-115, 2005.

[22] F. Dawalibi and S. Member, "Earth Resistivity Measurement Interpretation Techniques," IEEE Power Eng. Rev, vol. 4, no. 2, pp. 374-382, 1984.

[23] Y. Liu, N. Theethayi, and R. Thottappillil, "An Engineering Model for Transient Analysis of Grounding System Under Lightning Strikes : Nonuniform Transmission-Line Approach,” IEEE Trans. Power Deliv, vol. 20, no. 2, pp. 722-730, 2005.

[24] B. Tang, X. Sun, and J. Zou, "Overview of Method for Reducing Grounding Resistance of Substation Grounding System," in International Symposium on Computers \& Informatics (ISCI), 2015, no. Isci, pp. 773-780.

[25] F. Dawalibi, S. Member, S. E. Services, N. Barbeito, and F. P. Corporation, "Measurements and Computations of the Performance of Grounding Systems Buried in Multilayer Soils," IEEE Trans. Power Deliv, vol. 6, no. 4, pp. 1483-1490, 1991.

[26] V. P. Androvitsaneas, I. F. Ganas, and I. A. Stathapulas, "Performance of Ground Enhancing Compounds During the Year," in International Conference on Lightning Protection (ICLP), Vienna, Austria, 2012, pp. 145-149.

[27] G. Eduful and J. E. Cole, "Palm Kernel Oil Cake as an Alternative to Earth Resistance-Reducing Agent," in Power Systems Conference and Exposition, PSCE '09, 2009, pp. 1-4.

[28] W. R. Jones and N. York, "Bentonite Rods Assure Ground Rod Installation in Problem Soils," IEEE Trans. Power Appar. Syst., vol. 75, no. 4, pp. 1343-1346, 1980.

[29] S. C. Lim, C. Gomes, M. Zainal, and A. Ab, "Preliminary Grounding Performance of Bentonite Mixed Concrete Encased Steel Cage under High Soil Resistivity Condition," in 8th Asia-Pacific International Conference on Lightning, Seoul, Korea, 2013, pp. 145-148.

[30] M. B. Kostic and N. S. Radovanovic, "Improvement of electrical properties of grounding loops by using bentonite and waste drilling mud," in Generation, Transmission and Distribution, 1999, pp. 1-6.

[31] Z. R. Radakovic and M. B. Kostic, "Behaviour of grounding loop with bentonite during a ground fault at an overhead line tower," in Generation, Transmission and Distribution, 2001, pp. 275-278.

[32] W. F. W. Ahmad, M. S. A. Rahman, and J. Jasni, "Chemical Enhancement Materials for Grounding Purposes," in Lightning Protection (ICLP), 2010, pp. 1-6.

[33] D. Edwards, "Report on Resistivity Tests RESLO Ground Enhancement Compound," Australia, 2005.

[34] H. E. Martínez, E. L. Fuentealba, L. A. Cisternas, H. R. Galleguillos, and J. F. Kasaneva, "A New Artificial Treatment for the Reduction of Resistance in Ground Electrode," IEEE Trans. Power Deliv., vol. 19, no. 2, pp. 601-608, 2004.

[35] R. Xiong, B. Chen, B. Zhou, and C. Gao, "Optimized Programs for Shaped Conductive Back fi 11 Material of Grounding Systems Based on the FDTD Simulations," IEEE Trans. Power Deliv., vol. 29, no. 4, pp. 1744-1751, 2014.

[36] G. R. Agent and U. Q. Prof, "Research on the Mechanism of Grounding Resistance-Reducing Agent and the Used Quantity Prof. Y an Huai-Liang, Sichuan Institute of Industry, People's Republic of China," in International Conference on Properties and Applications of Dielectric Materials, 1991, pp. 3-6.

[37] M.Kurtovic and S.Vujevic, "Earthing grid parameters with conductor surrounded by an additional substance," in IEE Proceedings - Generation, Transmission and Distribution, 2000, pp. 57-61.

[38] O. Vryonis, T. Andritsch, A. S. Vaughan, and P. L. Lewin, "Improved Lightning Protection of Carbon Fiber Reinforced Polymer Wind Turbine Blades: Epoxy / Graphene Oxide Nanocomposites," in IEEE Electrical Insulation and Dielectric Phenomena (CEIDP), 2016, pp. 635-638.

[39] F. P. Dawalibi, S. Member, and S. E. Services, "Behaviour of Grounding Systems in Multilayer Soils: A Parametric Analysis," IEEE Trans. Power Deliv, vol. 9, no. 1, pp. 334-342, 1994.

[40] D. Paul and S. Member, "DC Traction Power System Grounding," IEEE Trans. Ind. Appl, vol. 38, no. 3, pp. 818-824, 2002.

[41] M. A. Abd-allah, A. Said, and M. N. Ali, "Mitigation of Lightning Hazards at the More Sensitive Points in Wind Farms Using Ant-Colony Optimization Technique," Bull. Electr. Eng. Informatics, vol. 5, no. 2, pp. 144-158, 2016. 
[42] N. A. M. Hasni, H. Ahmad, N. A. M. Jamail, M. S. Kamaruddin, and S. S. Ridzwan, "Investigation of Potential Grounding Compound for Portable Applications," Int. J. Electr. Comput. Eng., vol. 7, no. 6, pp. 3140-3146, 2017.

[43] Y. Li, F. P. Dawalibi, J. Ma, and Y. Yang, "Analysis of a Steel Grounding System: A Practical Case Study," in Electric Power Supply Industry (CEPSI), 2004, pp. 1-8.

[44] F. Mahtar, A. Ramli, W. R. W. Abdullah, and M. N. Isa, "Comparison Study of Usage as Grounding Electrode between Galvanized Iron and Copper with and without Earth Additive Filler," in Asia Pacific Conference on Applied Electromagnetic APACE, 2007, pp. 1-5.

[45] R. Gong, J. Ruan, Y. Hu, Y. Wu, and S. Jin, "Research on flexible graphite-copper composited electrical grounding material," in International Conference on AC and DC Power Transmission ACDC, 2016, no. 8.

[46] R. Gong, J. Ruan, Y. Hu, H. Ge, and S. Jin, "Performance comparison between flexible graphite-copper composited grounding material and conventional grounding materials," in International Conference on High Voltage Engineering and Application ICHVE, 2016, pp. 1-4.

[47] M. Z. A. A. Kadir and C. Gomes, "Performance of Backfill Materials Under Impulse and AC Testings," in International Conference on Lightning Protection (ICLP), 2012, pp. 1-7.

[48] Y. Hu, Y. An, R. Xian, and H. Li, "Study on Magnetic Properties of Flexible Graphite Composite Grounding Material,” IEEE Int. Conf. High Volt. Eng. Appl., no. 1, pp. 1-4, 2016.

[49] W. Hu et al., "A Testing Research on the Effect of Conductive Backfill on Reducing grounding Resistance under Lightning," in International Conference on Lightning Protection (ICLP), Vienna, Austria, 2012, pp. 1-4.

[50] Z. Burhanuddin, C. Gomes, A. Gomes, M. Z. K. A. Kadir, W. F. W. Ahmad, and N. Azis, "Characteristics of fulgurite-like structures under HV conditions: Effects on electrical earthing systems," in International Conference on Lightning Protection (ICLP), 2016.

[51] R. P. Tshubwana, T. Shongwe, and C. Gomes, "Characteristics and performance of Soil, Bentonite and Conductive cement during impulse tests in Swaziland," in International Conference on Emerging Technological Trends [ICETT], 2016, pp. 1-6.

[52] V. P. Androvitsaneas, I. F. Gonos, and I. A. Stathopulos, "Transient Impedance of Grounding Rods Encased in Ground Enhancing Compounds," in IEEE Lightning Protection (ICLP), 2014, pp. 359-363.

[53] R. Araneo, M. Maccioni, and S. Lauria, "Analysis of the Lightning Transient Response of the Earthing System of Large-Scale Ground Mounted PV Plants," in PowerTech, 2017, pp. 1-6.

[54] O. Ukar and I. Zamora, "Wind farm grounding system design for transient currents," Renew. Energy, vol. 36, no. 7, pp. 2004-2010, 2011 